\title{
Use of a general information and communication technology aspect for a specific aim
}

Susan Eley's letter (Eley, 1999) in fact describes and evaluates the use of an information and communication technology (ICT) tool in scientific research. I agree that characterization and evaluation of use of ICT in scientific research and education is of importance, since it may contribute to easier estimation of the possible adequate and effective use of the tool. I will discuss the issues raised by Susan Eley's letter systematically.

\section{Characterization}

In general characterization of an ICT tool results in an indication of one of the following types (COMMITT, 1996). (1) ICT as object: use of ICT as object is defined as the study of the computer and its applications, for example, making use of apparatus and programs in science and research. The relationship between the software and the subject of study is rather specific; (2) ICT as medium: use of ICT as medium mainly occurs in education, and relates to using the computer to mediate learning. Examples are 'Metabolic Pathways' (Wise, 1998), and the computer simulation programs Rat Model and Body Weight (Westerterp-Plantenga et al. 1994; Westerterp-Plantenga \& Kirschner, 1998). Often, these programs partly replace practical work (Kirschner, 1991; Westerterp-Plantenga \& Kirschner, 1998). Here also the relationship between the software and the subject of study is rather specific; (3) ICT as aspect: use of ICT as aspect relates to using the computer as a tool, for instance for collecting information, analysing data, modelling in natural sciences, and for communication using email or computer conferencing. The adequate software is rather general and can be used for the desired purposes. Thus, nutrition research using email as described in the letter is an example of a specific use of a general ICT aspect.

\section{Evaluation}

In general, dual evaluation of an ICT tool used for research is required. First, the degree to which the technical and content-related conditions are being met, should be evaluated (Westerterp-Plantenga \& Kirschner, 1998). Second, the degree of efficiency, effectiveness and satisfaction should be evaluated (Westerterp-Plantenga \& Kirschner, 1998).

From the letter it is clear that the technical conditions of using email are met to a certain degree. In comparison, it is of interest to realize that the postal service (surface- and airmail) has been shown to be a large, modest and international organization with a high quality of functioning, for 200 years (NRC-Handelsblad, 1999).

When ICT is used as an aspect, content-related conditions depend on what the user uses it for. In the application described in the letter, most of the conditions seem to be met to a certain extent, except generating a representative sample and preservation of the anonymity of the respondent.
Thus, depending on the aim of the study, the content may or may not meet the criteria.

With respect to evaluation of efficiency, effectiveness and satisfaction of using email for the purpose of nutrition research, the letter describes a relatively high level of efficiency. In general, effectiveness is related to the degree to which the content conditions are met, and thus to the quality of the observation. Satisfaction of using email is a subjective factor that stimulates or inhibits further use by the researcher as well as by the respondent. It is related to the extent to which the technical and content conditions are met, and it may also depend on the different psycho-sociological issues as described in the letter. For instance, generating a representative sample is related to the respondents' satisfaction, which thus contributes to the effectiveness and quality of the study.

In summary, discussing the use of email in nutrition research implies discussing the use of a general ICT aspect for a specific aim. Evaluation should include efficiency, effectiveness and satisfaction of using email for this purpose, taking into account the extent to which the content related and technical conditions are met. Careful reading of Susan Eley's letter throws some light on these issues in a qualitative and sometimes quantitative way.

\section{References}

COMMITT (1996) Teaching and Learning for the Future. Enschede: Secretariat Committ, University of Twente.

Eley S (1999) Nutrition research using electronic mail. British Journal of Nutrition 81, 413-414.

Kirschner PA (1991) Practicals in Higher Open Distance Learning. Dordrecht, The Netherlands: Lemma.

NRC-Handelsblad (1999) Post een wonder van beschaving (Mail, a miracle of civilization), pp. 31-35. Rotterdam, The Netherlands: NRC-Handelsblad.

Westerterp-Plantenga MS, Fredrix EWHM, Steffens AB, Kissileff HR (editors) (1994) Food Intake and Energy Expenditure. Heerien, The Netherlands and: OU and Boca Raton, FL: CRC Press.

Westerterp-Plantenga MS \& Kirschner PA (1998) Information and communication technology in nutrition and dietetic education. British Journal of Nutrition 79, 479-480.

Wise A (1998) Information technology in nutrition and dietetic education. British Journal of Nutrition 79, 547-550.

Margriet S. Westerterp-Plantenga
Department of Human Biology
Maastricht University
PO Box 616
6200 MD Maastricht
The Netherlands 